\title{
ROSENTAL ALVES
}

\section{“EL FUTURO DEL PERIODISMO DEPENDE MUCHO DEL EMPRENDIMIENTO Y DE LA INNOVACIÓN"}

\author{
Entrevista por: Paúl Mena Erazo
}

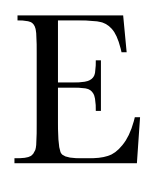

1 maestro Rosental Alves se ha dedicado por años a estudiar las grandes transformaciones que experimenta el mundo de los medios de comunicación y el periodismo. Ese interés lo ha llevado a dictar charlas en varios países del mundo, y lo trajo también a Ecuador, a la Conferencia Internacional Periodismo en Debate, que cada año organizan la Carrera de Periodismo Multimedios de la Universidad San Francisco de Quito y el Foro de Periodistas de Ecuador.

Rosental Alves, nacido en Brasil, ha tenido una larga trayectoria en el periodismo en lo profesional y en lo académico. Es el fundador y director del Centro Knight para el Periodismo en las Américas y es profesor de periodismo en la Universidad de Texas, en Austin. Previamente fue corresponsal en varios países y editor ejecutivo del diario brasileño Jornal do Brasil, donde laboró por 23 años.

En su charla en Quito, Rosental habló sobre el impacto de la incesante evolución tecnológica en el periodismo, hizo un análisis del futuro del periodismo en la era digital, y también advirtió que hoy en la web "no todo lo que parece periodismo, es periodismo, muchos están comprando gato por liebre". 
Terminada su intervención, Rosental dedicó un tiempo para esta entrevista, en la que hablamos de innovación en los medios, emprendimiento, los valores éticos del periodismo, la situación de la prensa en países como Ecuador y las oportunidades para los nuevos periodistas. Fueron unos 30 minutos de un diálogo muy interesante, que luego continuó en varios momentos de aquella Conferencia Periodismo en Debate.

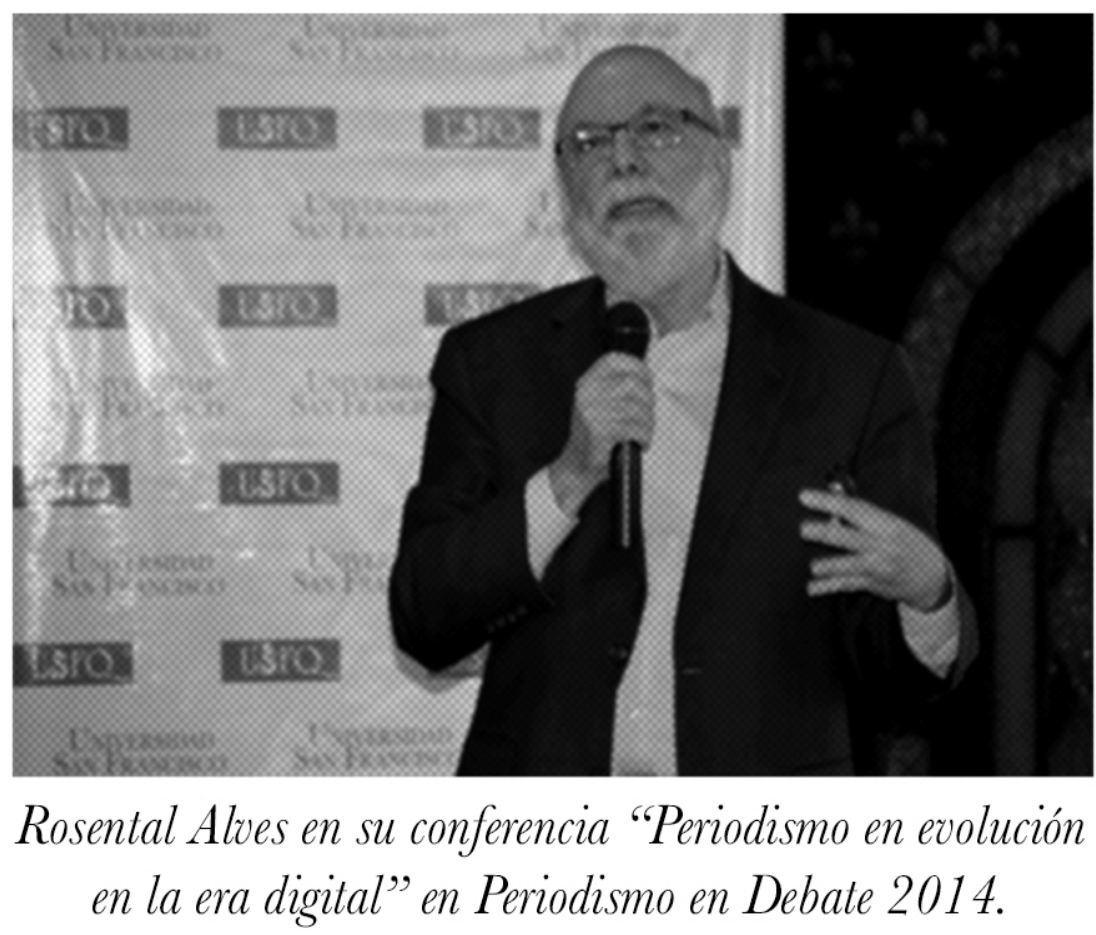

\section{¿Cómo ves el futuro del periodismo?}

La revolución digital es un proceso largo que no solo tiene que ver con internet sino que son cambios paradigmáticos que se están procesando y que van a seguir en las próximas décadas. Esta revolución digital es comparable con muy pocos momentos de la historia de la humanidad, como la palabra escrita en la Grecia antigua, el aparecimiento de la imprenta y la revolución industrial. Esos momentos son todos ligados a la comunicación, y al manejo, producción, distribución y consumo de información. Lo que se ve ahora es que empezó un proceso de ruptura del sistema mediático que había sido construido durante la Revolución Industrial y que estaba vigente hasta hace muy poco tiempo. Se ve la creación de un nuevo sistema que guarda un paralelo con el sistema biológico o económico y que es cada vez más diferente del sistema mediático que había en el siglo XX. No quiere decir que el sistema anterior vaya a morir de un día para otro, pero ese sistema mediático anterior se está cambiando radicalmente. 
Como he mencionado en charlas, el libro de Roger Fidler llamado Mediamorphosis: Understanding New Media señala que, a través de la historia, aunque la llegada de los medios nuevos siempre causaba la impresión de que los medios viejos iban a desaparecer, los medios nuevos en realidad se acomodaban dentro del conjunto de medios que ya existían. Los medios viejos cambiaban, se tornaban diferentes, pero sobrevivían. No obstante, yo hace más de 15 años reté esa posibilidad para describir lo que se iba a dar con los medios con la revolución digital. Creé la palabra mediacidio para decir que aquel sistema de medios que existía en ese momento va a desaparecer algún día y en lugar de él va a aparecer un nuevo sistema. Equivocadamente se vio a la web como simplemente un nuevo medio que se juntaría en un proceso de mediamorfosis como el descrito por Fidler. Pero la web es solo la punta de un iceberg que es la gran revolución digital, y lo que la web representa, más que un nuevo medio, es una fuerza transformadora de los medios.

El periódico, como un medio de masa con unos 200 años de existencia, ya había visto llegar a grandes y potentes medios nuevos, como fue en su tiempo la radio y después la televisión. En esas dos ocasiones se decía que el periódico iba a desaparecer porque la gente no iba a comprar el periódico para saber noticias de ayer que ya había escuchado en la radio o visto en la televisión, o que la radio iba a desaparecer porque la TV era la radio con imágenes. Sin embargo esto no ocurrió porque estos medios se acomodaron. El periódico se adaptó. Se disminuyó el número de ediciones, ya que había muchas ediciones durante el día en las grandes ciudades del mundo. A su vez la radio se adaptó cuando llegó la TV. Así, el periódico siguió siendo periódico y la radio siguió siendo radio.

Lo que viene ahora con la era digital es una transformación tan grande que hoy por hoy, por ejemplo, el periódico no es más el periódico. El periódico impreso mono media como teníamos hace 20 años no existe más. Tal periódico entró en un proceso de transformación mucho más grande que la mediamorfosis de la que Fidler habla. Es un proceso de transmutación en la que el periódico deja ser solo el periódico y se convierte en una central de información multimedia. Entonces ya no es el mismo que antes. Y la televisión tiene primera plana, y el periódico tiene video, y la radio tiene fotografia. Es una mezcla de todo que todavía no para de cambiar. Es un proceso largo.

Cuando se estudia la crisis de los medios llamados "tradicionales" muchas veces se da énfasis en la creación de nuevos medios. Y es verdad que hoy se pueden crear nuevos medios en Internet, pero hay quienes se preocupan porque los niveles de audiencia, y de infuencia, de tales emprendimientos son en muchos casos bastante menores que los niveles de audiencia de los medios tradicionales. ¿Crees que al final del día van a prevalecer los nuevos medios que están desarrollándose?

Hay que mirar a mercados más desarrollados donde el proceso ya se dio de una u otra manera. En el mercado estadounidense, uno tiene medios que nacieron en internet 
con mucha menos inversión de la que sería necesaria para hacer un medio tradicional y que tienen tanto o más audiencia e influencia que los medios tradicionales. Hace unos años preguntaba ¿en qué zapatos quieres estar? ¿en los zapatos del New York Times que está disminuyendo o en el del Huffington Post que está creciendo? Uno es enorme. El otro es pequeño. El uno no crece, sino que disminuye, y el otro está creciendo rápidamente. Hay medios pequeños que tienen costos muy bajos y que pueden permanecer y tener una voz importante, aún en nuestros países, y que se están consolidando como marcas y como medios creíbles. En el caso colombiano, tomo como ejemplo La Silla Vacía. Es un medio pequeño, puramente de internet, pero que en pocos años se puso a la par con los grandes medios en materia de influencia. Todavía no tiene un esquema comercial tan lucrativo como los medios tradicionales pero es un patrimonio que ha sido creado.

En Estados Unidos, muchos blogs unipersonales que fueron hechos con mucho trabajo, sin ganar nada por mucho tiempo, después se tornaron en empresas de medios que contrataron a gente. Así que hay que tener paciencia con los nuevos medios y ser creativo en cómo crear nuevas fuentes de ingreso que no sean solamente la publicidad.

En este contexto, si nos referimos a periodistas jóvenes, a estudiantes de periodismo, que se preocupan por el futuro de su profesión, ¿cuál es el mejor norte para ellos: aspirar a trabajar en medios tradicionales o crear un medio propio? ¿a dónde ellos deberían proyectarse?

Estos últimos años me he dedicado a dar una clase de periodismo emprendedor que trata de responder justamente a esa pregunta. En lugar de esperar que le den un trabajo en los medios tradicionales, el estudiante de periodismo debe tratar de crear su propio trabajo, porque la mejor manera de conseguir un trabajo estable en una empresa de medios es demostrar lo que cada persona es capaz de hacer.

El futuro del periodismo depende mucho del emprendimiento y de la innovación, que no son características comunes en las salas de redacción tradicionales. Las salas de redacción tienen su propio sistema y métodos, y normalmente quieren seguir haciendo lo que hacen de la forma en la que lo hacen. Pero eso no es suficiente en un mundo donde el ecosistema mediático está cambiando tanto. Necesitamos descubrir nuevas formas de hacer cosas. Una vez le dijeron a Thomas Alva Edison: "Pero usted falló 140 veces antes de la invención del foco" Y él dijo: No, yo no fracasé. Yo tuve éxito 140 veces porque estuve todas esas veces probando los materiales que pudieran sostener el foco, sin producir calor ni fuego en demasiado. Esa es la esencia del espíritu innovador. No hay que lamentar fracasos, cuando esos fracasos le enseñan a uno lecciones para el nuevo intento. Es experiencia ganada que te permite seguir adelante.

Un 95\% de los emprendimientos que nacen en Estados Unidos fracasan, sin embargo los financistas siguen poniendo dinero allí, pues un emprendimiento que resulte paga toda la inversión de los otros. 
Mi consejo es que los estudiantes tengan un blog o sitio Web, que descubran un nicho, que busquen un modelo de negocio que pueda funcionar, y que no se queden esperando a que alguien les de empleo, porque la gente que tiene empleo para dar valora mucho ese espíritu emprendedor y de innovación.

¿Recuerdas la famosa discusión publicada en 2013 en The Nerw York Times entre Bill Keller, a la fecha editor del diario neoyorquino, y Glenn Greenwald, entonces columnista de The Guardian, en la que se evidenciaron dos formas diferentes de ver el periodismo, una más ligada a los principios periodísticos de independencia e imparcialidad, y la otra más dirigida hacia la defensa de la voz de autor de un periodismo que tome más partido por causas? En este tema que estamos hablando en esta entrevista, de los nuevos medios y el emprendimiento, ¿cómo ubicaría la discusión entre Kellery Greenzuald? ¿ Por qué línea deberían ir los nuevos medios con sus herramientas y tecnologías?

No quiero entrar en la discusión específica que los dos mantuvieron, pero sí puedo decir que en la cacofonía que se crea en redes sociales y en internet en general, el rol mediador del periodismo como una voz profesional, ética e imparcial tiene un lugar si trae los valores básicos que se han construido en el periodismo de calidad en los últimos 100 años. Hay algunas personas que están creando nuevas fórmulas en internet que no tienen la preocupación de ese compromiso periodístico y creen que pueden cambiar el sistema deontológico que hay en el periodismo.

La credibilidad es la cosa más difícil de construir y creo que los valores del periodismo tradicional pueden ser adaptados a los nuevos medios, aunque algunas cosas van cambiando. Por ejemplo, el periodismo se había vuelto muy determinista tecnológicamente y el periodista como autor había desaparecido. Usar la primera persona en una nota era muy difícil, o saber algo sobre el autor era casi imposible. Esas son cosas que están cambiando. La nueva objetividad es la transparencia. Tener una voz en la nota, saber quién es el periodista, o en general transparentar todo el proceso periodístico es una de las cosas nuevas, pero no es incompatible con los valores éticos. Así que creo en la transposición de los valores del ecosistema anterior al periodismo de este nuevo sistema. No hay incompatibilidad en este sentido. Hay adaptaciones, hay cambios, hay cosas que no se hacía y ahora sí se hacen.

\section{¿Qué crees de las iniciativas que se muestran como periodismo pero no lo son?}

El periodismo dejó de ser monopolio de los periodistas porque cualquier persona puede cometer actos de periodismo si está involucrada en un episodio del que conoce. Ahora ser testigo es muy diferente de lo que era antes. Ahora las personas en general están muchas veces por delante de los periodistas, están informando y tienen su audiencia. Pero hay que tener cuidado con esto porque muchas cosas que parecen ser periodismo, que tienen el mismo formato de periodismo, que informan, no son periodismo porque no están basadas en los principios éticos y deontológicos que tiene el periodismo. 
Hay muchos productos online hoy que parecen piezas periodísticas pero que no lo son. La gente no es estúpida, no se deja engañar con tanta facilidad como a veces nos parece. Por ejemplo, cuando hay una crisis y las redes sociales están muy por delante de lo que los medios dicen, la gente se está informando en las redes pero van al medio de comunicación creíble para chequear si eso es verdad porque sabe que el periodismo es una instancia verificadora que debe trabajar en base a principios profesionales. En un mundo en el que se crea tanta confusión, debe existir una alfabetización mediática o periodística. Y los medios tienen mucha obligación en explicar cómo hacen el trabajo periodístico y por qué lo hacen. Muchas veces las interpretaciones de los gobiernos sobre los medios se basan en una ignorancia de cómo los medios funcionan.

\section{Justamente en la situación actual por la que está atravesando Ecuadory otros países en la región en cuanto a una constante pugna gobiernos-medios, ¿cuál debería ser la mejor respuesta que los periodistas pueden dar?}

La mejor respuesta de los periodistas es hacer un buen periodismo. Hacer un periodismo de calidad que sea veraz y que muestre los procesos utilizados para llegar a las notas periodísticas. Cuando se politiza mucho y hay una guerra entre los gobiernos y los medios, el periodismo pierde porque se pierde espacio. En el caso de Ecuador, es anormal que un gobierno sea tan intolerante en relación a los medios de comunicación. No conozco los orígenes de esta confrontación, pero es una pena que los periodistas se vean en el medio de esa guerra, y también me da mucha pena ver a un presidente que es intolerante y beligerante con los medios de esa forma.

Es malo que en un momento tan delicado para la comunicación, donde los modelos de negocio de los medios tradicionales están siendo afectados por fuerzas externas enormes como Google o Facebook, se debilite el periodismo por razones políticas. Por otro lado, en Ecuador y otros países de la región, el gobierno crea sus propios medios y en esos medios aparentemente tampoco practica el periodismo que demanda de los medios privados sino que es un periodismo partidista y gobiernista.

\section{En todo caso, es una época de cambios y presión, pero también de oportunidades...}

Sí, es una época de muchas oportunidades especialmente para la gente joven que sabe manejar multimedia, que sabe manejar redes sociales, porque la comunicación está cambiando muy rápidamente. El ciudadano está ganando poder sobre la información. Mientras los medios y los gobiernos están en disputa, los ciudadanos están ganando más acceso a la información que nunca. 